\title{
Economic burden of time lost due to injury in NHL hockey players
}

Laura Donaldson $(\mathrm{PhD})^{1,2}$, Bing $\mathrm{Li}^{3}$, Michael D. Cusimano ${ }^{1,2}(\mathrm{MD}, \mathrm{PhD})$

${ }^{1}$ Division of Neurosurgery and Injury Prevention Research Office, St. Michael's Hospital

University of Toronto, 30 Bond Street, Toronto, Ontario, M5B 1W8, Canada

${ }^{2}$ Canadian Brain Injury and Violence Research Team

${ }^{3}$ Institute of Health Policy, Management and Evaluation, University of Toronto

Corresponding author: Michael D. Cusimano

Email: injuryprevention@smh.ca

Fax: 416 864-5857

Phone: 416 864-5312

Total word count: 1727

Keywords: Hockey, injury, economics

\section{ABSTRACT}


Objective: To determine the economic burden of salary costs lost due to injury in the National Hockey League (NHL). Methods: All NHL players who engaged in at least one regular season game during the 2009-10 to 2011-12 seasons comprised the study population. We performed a retrospective cross-sectional analysis of publically available media sources to collect injury and salary data. Outcome measurements were games missed during regular season play due to hockey-related injury and lost salary. Results: 50.9\% of all NHL players missed at least one game within a season of play and injuries represented a total salary cost of approximately US\$218 million yearly. Concussions alone amounted to a salary loss of $\$ 42.8$ million a year. Head/neck injuries and leg/foot injuries were the most expensive in terms of overall cost, while head/neck and shoulder injuries had the highest mean cost. Conclusions: NHL players commonly miss time due to injury, which creates a substantial burden in lost salary costs.

INTRODUCTION 
Employers are legally and ethically responsible for protecting the health and safety of their employees ${ }^{1}$. For professional athletes in contact sports, the risk of injury while competing is relatively high but is modified by using protective equipment and enforcing rules regulating player-player contacts during the game. Despite current injury prevention strategies, professional hockey is seen as a particularly risky sport and $31 \%$ of Canadian parents report that they would discourage their children from participating ${ }^{2}$. Recently, sponsors of the National Hockey League (NHL) have pressured the league to act in addressing injury risks ${ }^{3}$ and insurance companies, which cover a portion of salary cost for players with long-term injuries, are also expressing reluctance to continue to compensate teams ${ }^{4}$. Despite this, NHL management and players are resistant to making changes that could decrease speed and physical play and any changes to the game would have to be proposed in a way that makes financial sense to the league.

This study investigated the financial impact of injuries in the NHL measured by the amount of player salaries paid out to injured players between the 2009-10 and 2011-12 seasons.

\section{METHODS}

\section{Study sample and design}

A retrospective cross-sectional study was performed on all 1307 NHL players participating in regular season games in the 2009-10, 2010-11 and 2011-12 seasons. Consent was not required as all data were obtained from publicly available sources.

\section{Data collection}

Data sources: Full rosters and the number of games participated in by each player were obtained from the NHL website (www.nhl.com). Injury data were obtained from nhl.com, and 
official team injury reports. When more information was required, a variety of other publically available sources including The Sports Network (www.tsn.com), Yahoo Sports (sports.yahoo.com), and Rotoworld (www.rotoworld.com) were consulted. Annual player salaries (USD) were obtained from www.capgeek.com.

The increasing popularity of fantasy sports has resulted in a huge demand for information on the injury status of professional athletes. A study of injuries in professional basketball players found that media sources provided comprehensive and accurate injury information ${ }^{5}$, and media reports have also been employed previously to investigate the incidence of NHL concussions $^{6,7}$.

Injuries: The total number of games missed by each player during the entire regular season due to injury was determined. We defined "injury" as any hockey-related ailment that kept a player out of competition for at least one game or needed medical attention but may not have resulted in time lost from play (adapted from Stuart and $\mathrm{Smith}^{8}$ ). We excluded injuries occurring outside the league or those caused by nonhockey activities. We also recorded all concussions or suspected concussions occurring during the entire regular season. Because of the association with intracranial injuries, nonnasal facial fractures were included in concussion counts ${ }^{9,10}$. A small number of injuries had to be categorized as "undisclosed". Injury cost calculation: Annual player salaries in US dollars (USD) were divided by 82 (number of regular season games) to obtain a per game salary for each player (players do not receive additional salary from their team for playoff games). We multiplied this amount by the number of regular season games missed by that player due to injury. Injuries by body region: To estimate costs for injuries to different regions of the body, a subset of injuries occurring during a random sample of ten regular season weeks from each of the three NHL seasons was analyzed to determine 1) the body part injured and 2) the number 
of games missed due to the injury. The category head/neck includes concussions as well as other types of injury (e.g. contusion, laceration).

Insurance cost calculation: Insurance companies compensate teams $80 \%$ of salary costs for

players injured more than 30 games due to a single injury ${ }^{11}$. We identified all concussions and all single injuries in our random sample that resulted in the player being out for more than 30 games. The insurance cost of the injury was calculated by determining the number of games missed in excess of 30 and multiplying this number by the per game salary, then multiplying by 0.80 .

\section{Statistical analysis}

Statistical analysis was performed with STATA v12.

For full details, see Supplemental Methods.

\section{RESULTS}

Within the three season time period analyzed, 825 of the 1307 NHL players $(63.1 \%)$ missed at least one game due to injury. Within a single 82 game regular season, $50.9 \%$ of all players were out injured for one game or more. The mean number of games missed was 8.8 (95\% CI: 8.0, 9.5), which corresponded to $11.0 \%$ of the regular season (95\% CI: 9.8, 11.6). The mean salary cost associated with a player missing games because of injury during a single season was US\$260,300 (95\% CI: $\$ 228,100, \$ 304,000)$ and the total lost salary costs due to injury over the three-year study period was $\$ 653$ million (\$218 million annual average).

323 concussions or suspected concussions occurred throughout the three seasons, with a mean salary cost of $\$ 397,700(95 \% \mathrm{CI}: \$ 312,900, \$ 482,500)$ and a total salary cost of $\$ 128.5$ million ( $\$ 42.8$ million annual average). $10.5 \%$ of concussions or suspected 
concussions during the three season study period resulted in more than 30 regular season games lost, representing a "concussion" cost to insurance companies of \$21.6 million and $\$ 44.9$ million to teams ( $\$ 7.2$ and $\$ 15.0$ million yearly).

We also investigated a subset of injuries occurring in a random sample of 10 weeks from each of the three seasons to determine the most costly types of injury. There were a total of 870 NHL injuries that occurred in this 30 week sample (95\% CI: 833, 906; 1423 total games). Overall, leg/foot injuries and head/neck injuries accounted for the highest proportion of injury costs, while head/neck and shoulder injuries had the highest mean cost per injury (Table 1$)$. Injury cost varied by body part injured $\left(\mathrm{F}_{8,869}=2.36, \mathrm{p}=0.017\right)$, but not by season $\left(\mathrm{F}_{8,869}=0.35, \mathrm{p}=0.70\right)$ and there was no significant interaction between the two variables $\left(\mathrm{F}_{16}\right.$, $\left.{ }_{869}=0.47, \mathrm{p}=0.96\right) .4 .1 \%$ of the injuries resulted in more than 30 regular season games lost, representing \$36.1 million in costs to teams and \$18.8 million to insurance companies.

Table 1. Salary costs of NHL injuries by Body Region in a 30 week sample.

\begin{tabular}{|c|c|c|c|c|c|}
\hline Injury Type & Number & $\begin{array}{c}\text { Mean Games } \\
\text { Missed }(95 \% \mathrm{Cl})\end{array}$ & $\begin{array}{c}\text { Mean Salary Cost } \\
\text { USD }(95 \% \mathrm{Cl})\end{array}$ & $\begin{array}{c}\text { Total Cost } \\
\text { (Millions of USD) }\end{array}$ & $\begin{array}{l}\text { Percentage } \\
\text { of Total Cost }\end{array}$ \\
\hline Leg/Foot & 241 & $\begin{array}{c}9.9 \\
(8.3,11.4)\end{array}$ & $\begin{array}{c}\$ 283,100 \\
(\$ 220,800, \$ 345,400)\end{array}$ & $\$ 68.2$ & 30.0 \\
\hline Head/Neck & 165 & $\begin{array}{c}11.1 \\
(8.8,13.5)\end{array}$ & $\begin{array}{c}\$ 353,300 \\
(\$ 242,100, \$ 464,500)\end{array}$ & $\$ 58.3$ & 25.7 \\
\hline Shoulder & 88 & $\begin{array}{c}10.2 \\
(8.1,12.4)\end{array}$ & $\begin{array}{c}\$ 306,600 \\
(\$ 213,000, \$ 400,100)\end{array}$ & $\$ 27.0$ & 11.8 \\
\hline Groin & 108 & $\begin{array}{c}7.0 \\
(5.6,8.4)\end{array}$ & $\begin{array}{c}\$ 203,900 \\
(\$ 156,500, \$ 251,300)\end{array}$ & $\$ 22.0$ & 9.7 \\
\hline Arm/Hand & 75 & $\begin{array}{c}10.3 \\
(8.0,12.6)\end{array}$ & $\begin{array}{c}\$ 290,000 \\
(\$ 181,200, \$ 398,800)\end{array}$ & $\$ 21.8$ & 9.6 \\
\hline Chest/Abdomen & 66 & $\begin{array}{c}7.1 \\
(5.4,8.9)\end{array}$ & $\begin{array}{c}\$ 219,400 \\
(\$ 128,900, \$ 310,000)\end{array}$ & $\$ 14.5$ & 6.4 \\
\hline
\end{tabular}




\begin{tabular}{|c|c|c|c|c|c|}
\hline $\begin{array}{c}\text { Lower Body - } \\
\text { Unspecified }\end{array}$ & 62 & $\begin{array}{c}4.0 \\
(3.0,5.0)\end{array}$ & $\begin{array}{c}\$ 117,400 \\
(\$ 82,200, \$ 152,600)\end{array}$ & $\$ 7.3$ & 3.2 \\
\hline $\begin{array}{c}\text { Upper Body - } \\
\text { Unspecified }\end{array}$ & 52 & 4.2 & $\$ 126,600$ & $\$ 6.6$ & 0.4 \\
\hline Undisclosed & 13 & $(3.0,5.4)$ & $(\$ 65,200, \$ 188,000)$ & $\$ 0.86$ & 100 \\
\hline
\end{tabular}

A sample of 870 injuries was selected by tabulating all injuries occurring in a 10 week sample from each of the three seasons. Injury types and mean numbers of games missed for NHL players suffering injuries to specific regions of the body are shown along with the mean and total salary costs in US dollars (USD) associated with lost time and the proportion of the total cost contributed by each injury type. $95 \%$ confidence intervals are shown in brackets.

\section{DISCUSSION}

Our analysis reveals that approximately one half of all NHL players suffer an injury resulting in a loss of playing time during each regular season of play. In our opinion, as well as in the eyes of fans and league sponsors ${ }^{2,3}$, this is an unacceptably high rate of injury for any workplace. The question of whether professional sports leagues are subject to the same requirements to protect employee safety that are laid out for other workplaces in the Occupational Health and Safety Act is a matter of debate ${ }^{12}$. The National Institute for Occupational Safety and Health has not historically dealt with injuries in professional athletes, but has been involved in investigating neurotraumatic injuries in former football players $^{13}$.

To address injuries, and specifically concussions, the NHL has recently introduced changes to bodychecking rules. Hitting to the head of another player from his blindside was 
made illegal in 2010-11 and hitting to the head from any direction was made illegal under almost all circumstances for the 2011-12 season ${ }^{14,15}$. Initial data have not shown any effect of this rule in decreasing the number of concussions players are suffering ${ }^{7}$ and players and management have been reluctant to implement more drastic changes such as banning fighting $^{16,17}$, though fighting accounts for approximately 8-9\% of concussions in the current $\mathrm{NHL}^{7,18}$.

One argument against imposing restrictions on aggressive player-player contacts is that violence and physicality are thought to be tied to increased team revenues ${ }^{19-21}$. We suggest that taking such measures to decrease player injuries may not result in financial losses as salary costs directly resulting from games missed due to injury represent a substantial economic burden for NHL teams and their insurers. Added to this are the costs of treating injuries, which were not included in this study. It is possible that a small number of injuries may have been missed, as we employed public injury reports and did not have access to medical records. There are also other costs to consider, which cannot easily be quantified. Popularity of the game and of an individual team can suffer when star players like Sidney Crosby or Marc Savard are injured, resulting in lower attendance and merchandising earnings. In addition, the pain and suffering that athletes must cope with must be considered. Athletes must also deal with chronic sequelae of their injuries, which is particularly concerning in the case of concussion. There are multiple published case series describing cognitive and psychological impairment in former athletes with a history of head trauma including hockey players, football players and boxers ${ }^{22,23}$ and the long term costs of these conditions have not been measured in our study. The short and long-term financial effects that aggressive play in the NHL has on the players in less elite and youth leagues would also be significant given the strong social influence that professional play has on these groups 


\section{CONCLUSION}

While league owners and management are wary of making changes to the game to decrease aggression that could in turn affect profits, they must also consider the costs of injuries. We have determined the estimated cost in lost salary for all injuries, and specifically for concussion, to NHL teams, and their insurers. While salary losses represent a significant financial burden, this is only one component of the true cost of player injuries. The full cost of these injuries is greater than what we have estimated and would include costs of treatment and personal suffering including long-term sequelae of injuries, potential later lost income and costs of future medical care, particularly for concussion. It is hoped that consideration of these costs will provide sufficient motivation for professional sports leagues like NHL to consider taking further action to prevent player injuries.

What is already known on this subject:

- NHL players are at risk for sustaining injuries in their workplace, including concussions and other severe or potentially chronic injuries

- Teams must continue to pay injured players their salaries, with insurance companies providing partial coverage for long-term injuries

What this study adds:

- We determine the direct economic impact of injuries in NHL players by calculating the total salary costs lost due to injuries, including the amount lost due to concussions. We also calculate the costs to insurers. 
- This work raises awareness of the costs of player injuries at the NHL and other levels and provides incentive for interventions to improve player safety

\section{ACKNOWLEDGEMENTS}

We would like to thank the group members of the Injury Prevention Research Office for helpful discussion.

\section{COMPETING INTERESTS}

The authors have no competing interests.

\section{FUNDING}

This research was supported by the Canadian Institutes of Health Research Strategic Team Grant in Applied Injury Research \# TIR-103946, the Ontario Neurotrauma Foundation, as well as University of Toronto Faculty of Medicine CREMS funding.

\section{CONTRIBUTORSHIP STATEMENT}

LD and MDC designed the study and wrote the manuscript. LD collected data and LD and BL analyzed data.

\section{REFERENCES}

1. Occupational Safety and Health Act of 1970.

2. Canadians, Hockey Fans Want to Ban Head Shots from the Game. Angus Reid Public Opinion. 2011, Nov 11. Available: http://www.angus-reid.com/polls/44111/canadians-wantto-ban-head-shots-from-hockey-but-no-consensus-on-fights/ (Accessed 2013 Sept 9). 
3. Head-shot controversy touches NHL's most sensitive area: its wallet. Mar 10, 2011. THN.com. Available: http://www.thehockeynews.com/articles/38974-Headshot-controversytouches-NHLs-most-sensitive-area-its-wallet.html (Accessed 2013 Sept 9).

4. NHL concussions put player insurance in question. CBC Sports. 2012, Jan 31. Available: http://www.cbc.ca/sports/hockey/nhl/story/2012/01/31/sp-insurance-nhl-concussions.html (Accessed 2013 Sept 9).

5. Orchard J, and Hayes J. Using the World Wide Web to conduct epidemiological research: an example using the National Basketball Association. Int Sport Med J 2001;2:1-15.

6. Wennberg RA, and Tator $\mathrm{CH}$. Concussion incidence and time lost from play in the NHL during the past ten years. Can J Neurol Sci 2008;35:647-51.

7. Donaldson L, Asbridge M, Cusimano MD. Bodychecking rules and concussion in elite hockey. PLoS One 2013;8:e69122.

8. Stuart MJ, Smith AM. Principles of ice hockey injury research. ASTM Special Technical Publication 2000;1341:19-31.

9. Keenan HT, Brundage SI, Thompson DC et al. Does the face protect the brain? A casecontrol study of traumatic brain injury and facial fractures. Arch Surg 1999;134:14-17. 10. Pappachan B, Alexander M. Correlating facial fractures and cranial injuries. J Oral Maxillofac Surg 2006;64:1023-1029.

11. Daly B. Concussion claims won't hurt NHL financially. The Globe and Mail. Jan 31, 2012. Available: http://sports.nationalpost.com/2012/01/31/concussion-claims-wont-hurt-nhlfinancially-bill-daly/ (Accessed 2013 Sept 9).

12. Monette M. Heavy hitting: concussions and safety law. CMAJ 2012;184:E641-2.

13. Lehman EJ, Hein MJ, Baron SL, et al. Neurodegenerative causes of death among retired National Football League players. Neurology 2012;79:1970-4.

14. National Hockey League Official Rules 2010-11. The National Hockey League. 2010. 15. National Hockey League Official Rules 2011-12. The National Hockey League. 2011. 16. NHLPA Player Poll. Jan 2012. Available: http://www.playerspoll.ca/ (Accessed 2012 Sept 9).

17. Schoalts D. NHL won't even consider banning fights. The Globe and Mail. Dec 6, 2011. http://www.theglobeandmail.com/sports/hockey/nhl-wont-even-consider-banningfights/article1357795/ (Accessed 2013 Sept 9). 
18. Hutchison MG, Comper P, Meeuwisse WH, et al. A systematic video analysis of National Hockey League (NHL) concussions, part II: how concussions occur in the NHL. Br J Sports Med 2013. Published online Jun 13.

19. Jones JCH, Stewart KG, Sunderman R. From the arena into the streets: Hockey violence, economic incentives and public policy. Am J Econom Sociol 1996;55:231-243.

20. Paul RJ. Variations in NHL attendance: the impact of violence, scoring, and regional rivalries. Am J Econom Sociol 2003;62:345-364.

21. Haisken-DeNew JP, Vorell M. Blood Money: Incentives for Violence in NHL Hockey. Ruhr Economic Papers. 2008;47:1-30.

22. McCrory P. Sports concussion and the risk of chronic neurological impairment. Clin J Sport Med 2011;21(1):6-12.

23. Caron JG, Bloom GA, Johnston KM, et al. Effects of multiple concussions on retired national hockey league players. J Sport Exerc Psychol 2013;35:168-79. 